\title{
Socio-economic factors associated with the degradation of quality of life of individuals with blindness and visual impairment in Yaoundé
}

\author{
Alexis Nkouellé ${ }^{1}$, Hénock Blaise NguendoYongsi $2,{ }^{*}$, Emilienne Epée ${ }^{1}$ and Olga Yvonne Bassong Mankollo ${ }^{1}$ \\ ${ }^{1}$ Department of Public Health, School of Health Sciences, Central Africa Catholic University, Cameroon. \\ 2 Institute for Training and Demographic Research (IFORD), University of Yaoundé II, Cameroon.
}

Publication history: Received on 21 August 2020; revised on 09 September 2020; accepted on 12 September 2020

Article DOI: https://doi.org/10.30574/gscbps.2020.12.3.0273

\begin{abstract}
Blindness and visual impairment are currently considered as major health issues worldwide, as they affect all age groups and have a major impact on the quality of life of individuals. The objective of this study was to determine the socio-economic factors associated with the deterioration of quality of life, and to assess blindness and visual impairment influence on the autonomy of individuals. This is a cross-sectional epidemiological study conducted on blind and visual impaired persons in Yaoundé in 2015. A total of 45 visual impairment individuals were interviewed, including 26 men (57.8\%) and 19 women (42.2\%). The average age was $34.66 \pm 10.57$ years. Findings showed that there is a relationship between visual impairment and the level of autonomy. The ANOVA test has shown that, there are differences in autonomy according to variables such as occupation $(F=7.303 ; p=0.000)$; education $(F=7.556 ; p=0.002)$; income $(F=$ 21.563; $\mathrm{p}=0.000$ ). Blind and visual impaired persons who have sustainable employment, a sufficiently high level of income and a sustainable source of income have a higher level of independence. The socio-economic factors highlighted in this study interact and influence visual impairment persons' autonomy.
\end{abstract}

Keywords: Blindness; Visual impairment; Socio-economic factors; Quality of Life; Autonomy; Yaoundé.

\section{Introduction}

In Cameroon, it is estimated that 540,000 persons are visually impaired, including 180,000 visual impairment people [1]. Because of their disability, visual impairment people are disadvantaged by physical and social barriers that prevent them from participating in many activities. As a result, they are marginalized and do not always benefit from measures to overcome difficulties in order to achieve their full potential. This situation negatively affects their quality of life [2]. Once visual impairment has set in, a person's quality of life deteriorates. This deterioration affects all life components, be the limitation of activities or social, professional and family disruptions, but also the psychological impact [3]. Healthrelated quality of life can be defined as the set of conditions related to health status that diminish well-being, performance, and interfere with social roles and or alter the psychological functioning of the individual [3]. Quality of life is currently a major issue in the field of health.Taking it into account stems from the legitimate desire of the medical community and health authorities to know how patients live their health condition. Quality of life is an individual's conception of one's position in life, in the cultural context and value system in which he or she finds himself or herself, in relation to his or her goals, expectations, models and interests [4]. Autonomy is someone's ability not to be dependent on others, the right of an individual to determine himself or herself freely. Actually, it is a matter of identity, project, self-image. It presupposes the capacity for judgement, i.e. the ability to foresee and choose, and the freedom to be able to act, accept or refuse according to one's judgement. This freedom must be exercised in accordance with the law and common practice. A person cannot be considered autonomous without having a certain number of dependencies

\footnotetext{
${ }^{*}$ Corresponding author: H. Blaise NguendoYongsi

Institute for Training and Demographic Research (IFORD), University of Yaoundé II, Cameroon.
} 
towards his or her environment, while being able to manage these dependencies according to his or her own rules. The terms autonomy and dependency are not opposed, since autonomy refers to the free-will of the person, whereas dependency is defined by the need for help. In this study, we would like to identify the socio-economic factors associated with the deterioration of quality of life and highlight their influence on the autonomy of the visual impairment people in Yaoundé, as we believe results could be of use for their empowerment.

\section{Methods}

A descriptive cross-sectional study with an analytical aim was conducted over a period of 03 months, from August to November 2015 in the city of Yaoundé. Our population consisted of visual impairment people aged 15 years and more. A convenience sampling of 45 visual impairment persons were selected for investigation. Data were collected using standardized questionnaires, and entered using CS Pro version 6.0 software. Data processing and analysis was done using SPSS version 20.0 and Microsoft Excel 2016.

The variables studied were: level of education, occupation, braille training, adapted academic training, adapted vocational training, braille skills, access to information by computer with output in voice synthesis or braille, employment status, level of income, and character of the source of income. The general level of autonomy of each respondent was assessed on a five-point scale, with a score ranging from 1 to 5 (Table 1).

Table 1 Autonomy score

\begin{tabular}{|l|l|}
\hline Level of autonomy & Score \\
\hline Very low & 1 \\
\hline Low & 2 \\
\hline Medium & 3 \\
\hline High & 4 \\
\hline Very high & 5 \\
\hline
\end{tabular}

Four types of autonomy were assessed using predefined variables: physical autonomy, intellectual autonomy, socioeconomic autonomy, and psychological autonomy. General autonomy score = sum of the scores of the four types of autonomy /4. We proceeded to the calculation of the means and the frequencies for the univariate analysis. Concerning the bivariate analysis, according to the application criteria, the Chi-square test of independence, Cramer's $\mathrm{V}$ and the one-factor ANOVA test were used to look for associations between the variables retained in the study and the general autonomy of the visual impairment person. The variables were tested at a significance level of less than $5 \%(p$ $\leq$ 0.05). For the multivariate analysis, principal component analysis (PCA) was performed. With regard to ethical consideration, confidentiality and fairness were duly respected during the study. A consent form was signed by each participant. This study was approved by the Institutional Ethics Committee for Research in the Human Sciences (CEIRSH) of the School of Health Sciences of the Catholic University of Central Africa No. 2015/0145/CEIRSH/ESS/MSP.

\section{Results}

\subsection{Uni-variate analysis}

A total of 45 visual impairment persons aged 17-59 were interviewed, including 26 men (57.8\%) and 19 women (42.2\%). The average age was $34.66 \pm 10.57$ years. The first quartile was 27 years old; the median was 35 years old and the third quartile was 42.5 years old. These people were scattered in all the quarters of the city of Yaoundé. 18 (40\%) resided in Yaoundé IV, of which 12 (26.2\%) lived in the Ekounou quarter, including Ekié. Out of all the respondents, 25 $(56.6 \%)$ had secondary education level. 13 respondents $(28.9 \%)$ were pupils or students. 35 (77.8\%) of the respondents were jobless or not employed. 31 (68.9\%) were single. 21 (46.7\%) had no income. In terms of the level of autonomy, after assessment, 17 respondents (37.8\%) had a low level of general autonomy.

\subsection{Bi-variate analysis}

For the Chi-square test, there is a relationship between the level of autonomy and the following variables: level of education ( $p=0.0483)$, occupation $(\mathrm{p}=0.0191)$, braille training received $(\mathrm{p}=0.0016)$, braille skills $(\mathrm{p}=0.000)$, adapted 
academic training received $(\mathrm{p}=0.002)$, access to information by computer with output in voice synthesis or braille ( $\mathrm{p}=$ $0.0315)$, employment status $(\mathrm{p}=0.0001)$, income level $(\mathrm{p}=0.0)$, and the character of the source of income $(\mathrm{p}=0.0011)$. In addition, there is a very strong relationship between the level of autonomy and the employment status of the individual (Cramer's V = 0.744). Visual impairment persons who have sustainable employment, a high level of income and a sustainable source of income have a very high level of independence (Table 2).

Table 2 Chi-square test and Cramer's V

\begin{tabular}{|l|l|l|l|l|}
\hline Variables & Chi-square & DF & p & Cramer's V \\
\hline Socio-economic variables & & & & \\
\hline Education level & 15.6113 & 8 & 0.0483 & 0.416 \\
\hline Occupation & 35.1953 & 20 & 0.0191 & 0.442 \\
\hline Have received braille training & 17.449 & 4 & 0.0016 & 0.623 \\
\hline Braille skills & 32.950 & 8 & 0.000 & 0.605 \\
\hline Have received adapted academic training & 16.710 & 4 & 0.002 & 0.609 \\
\hline Have received adapted vocational training & 5.5372 & 4 & 0.2365 & 0.351 \\
\hline $\begin{array}{l}\text { Able to access information by computer with } \\
\text { output in voice synthesis or braille }\end{array}$ & 10.5977 & 4 & 0.0315 & 0.485 \\
\hline Employment status & 24.942 & 4 & 0.0001 & 0.744 \\
\hline Income level & 59.3397 & 16 & 0 & 0.574 \\
\hline Character of source of income & 25.9853 & 8 & 0.0011 & 0.537 \\
\hline
\end{tabular}

On the other hand, for one-way ANOVA, with regards to autonomy there are differences between : occupation groups $(F=7.303 ; p=0.000)$; education level groups $(F=7.556 ; p=0.002)$; income level groups $(F=21.563 ; p=0.000)$; and groups according to the character of the source of income ( $F=16.180 ; p=0.000)$ (Table 3$)$.

Table 3 One-way ANOVA

\begin{tabular}{|l|l|l|}
\hline \multicolumn{2}{|c|}{ Level of general autonomy } \\
\hline Socio-economic variables & F & Significance \\
\hline Occupation & 7.303 & 0 \\
\hline Level of education & 7.556 & 0.002 \\
\hline Have received braille training & 7.803 & 0.008 \\
\hline Braille skills & 9.035 & 0.001 \\
\hline Have received adapted schooling & 5.244 & 0.027 \\
\hline Have received adapted vocational training & 1.760 & 0.192 \\
\hline $\begin{array}{l}\text { Able to access information through adapted computer } \\
\text { technology }\end{array}$ & 9.15 & 0.004 \\
\hline Employment status & 31.046 & 0 \\
\hline Income level & 21.563 & 0 \\
\hline Character of source of income & 16.18 & 0 \\
\hline
\end{tabular}




\subsection{Multivariate analysis: Principal component analysis (PCA)}

On the basis of the main components, factor analysis by extraction shows that no variable is of poor quality in terms of variance percentage, although the adapted vocational training received does not exceed $41 \%$ of the percentage of variance (Table 4).

Table 4 Principal component analysis of factors by extraction

\begin{tabular}{|l|l|l|}
\hline Socio-economic variables & Initial value & Post-extraction value \\
\hline Level of education & 1.000 & .771 \\
\hline Occupation & 1.000 & .585 \\
\hline Have received braille training & 1.000 & .970 \\
\hline Braille skills & 1.000 & .973 \\
\hline Have received adapted schooling & 1.000 & .630 \\
\hline Have received adapted vocational training & 1.000 & .405 \\
\hline $\begin{array}{l}\text { Able to access information through adapted computer } \\
\text { technology }\end{array}$ & 1.000 & .799 \\
\hline Is employed & 1.000 & .881 \\
\hline Character of source of income & 1.000 & .673 \\
\hline Income level & 1.000 & .715 \\
\hline
\end{tabular}

After extraction, the analysis of variance shows that four main axes cover $74 \%$ of the total variance. This percentage is sufficiently satisfactory, given the nature of the data, and the eigenvalue of the first axis is greater than three (Table 5).

Table 5 Analysis of variance by extraction

\begin{tabular}{|l|l|l|l|l|l|l|}
\hline \multicolumn{2}{|l|}{ Total variance explained } \\
\hline \multirow{2}{*}{ Components } & \multicolumn{2}{|l|}{ Initial value } & \multicolumn{3}{l|}{ Extraction of sum of squares } \\
\cline { 2 - 7 } & Total & Variance \% & Cumulative \% & Total & Variance \% & Cumulative \% \\
\hline 1 & 3.030 & 30.297 & 30.297 & 3.030 & 30.297 & 30.297 \\
\hline 2 & 1.861 & 18.609 & 48.906 & 1.861 & 18.609 & 48.906 \\
\hline 3 & 1.505 & 15.047 & 63.953 & 1.505 & 15.047 & 63.953 \\
\hline 4 & 1.009 & 10.085 & 74.039 & 1.009 & 10.085 & 74.039 \\
\hline 5 & .837 & 8.370 & 82.409 & & & \\
\hline 6 & .791 & 7.905 & 90.314 & & & \\
\hline 7 & .453 & 4.531 & 94.845 & & & \\
\hline 8 & .404 & 4.044 & 98.889 & & & \\
\hline 9 & .111 & 1.110 & 99.999 & & & \\
\hline 10 & $5.221 \mathrm{E}-5$ & .001 & 100.000 & & & \\
\hline
\end{tabular}

Table 6 shows the Component Matrix after extraction. From this table, it can be seen that the component matrix after extraction shows that five variables are well represented on three main axes:

- On the first main axis: the character of the source of income;

- On the second main axis: braille training and braille skills;

- On the third main axis: the character of the source of income. 
Table 6 Component Matrix after extraction

\begin{tabular}{|l|l|l|l|l|}
\hline \multicolumn{2}{|c|}{ Socio-economic variables } & \multicolumn{4}{l}{ Components } & $\mathbf{3}$ & $\mathbf{4}$ \\
\cline { 2 - 5 } & $\mathbf{1}$ & $\mathbf{2}$ & $\mathbf{3}$ & .345 \\
\hline Occupation & -.346 & .073 & .376 & -.007 \\
\hline Braille skills & .078 & .957 & -.262 & -.012 \\
\hline Having received braille training & .077 & .956 & -.263 & .095 \\
\hline Character of income source & .521 & .276 & .539 & .095 \\
\hline
\end{tabular}

After extraction and rotation, the analysis of variance shows that four main axes cover $70 \%$ of the total variance. This percentage is sufficiently satisfactory, given the nature of the data. The eigenvalue of the first axis is greater than 2 , but it is possible to envisage the introduction of another component which has an eigenvalue of less than 1, but fairly close to 1 and its contribution is of the order of 9\%. Thus, the total inertia will be more than 79\% (Table 7).

Table 7 Analysis of variance by extraction then rotation

\begin{tabular}{|c|c|c|c|c|c|c|c|c|c|}
\hline \multicolumn{10}{|c|}{ Total variance explained } \\
\hline \multirow{2}{*}{ 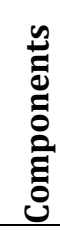 } & \multicolumn{3}{|c|}{ Initial Value } & \multicolumn{3}{|c|}{ Extraction of sums of squares } & \multicolumn{3}{|c|}{ Rotation of sums of squares } \\
\hline & Total & $\begin{array}{l}\text { Variance } \\
\%\end{array}$ & $\begin{array}{l}\text { Cumulative } \\
\%\end{array}$ & Total & $\begin{array}{l}\text { Variance } \\
\%\end{array}$ & $\begin{array}{l}\text { Cumulative } \\
\%\end{array}$ & Total & $\begin{array}{l}\text { Variance } \\
\%\end{array}$ & $\begin{array}{l}\text { Cumulative } \\
\%\end{array}$ \\
\hline 1 & 2.501 & 25.011 & 25.011 & 2.501 & 25.011 & 25.011 & 2.087 & 20.872 & 20.872 \\
\hline 2 & 2.160 & 21.602 & 46.613 & 2.160 & 21.602 & 46.613 & 1.970 & 19.704 & 40.576 \\
\hline 3 & 1.212 & 12.120 & 58.733 & 1.212 & 12.120 & 58.733 & 1.791 & 17.912 & 58.488 \\
\hline 4 & 1.156 & 11.556 & 70.289 & 1.156 & 11.556 & 70.289 & 1.180 & 11.801 & 70.289 \\
\hline 5 & .900 & 9.001 & 79.290 & & & & & & \\
\hline 6 & .723 & 7.229 & 86.519 & & & & & & \\
\hline 7 & .572 & 5.724 & 92.243 & & & & & & \\
\hline 8 & .510 & 5.097 & 97.340 & & & & & & \\
\hline 9 & .266 & 2.660 & 99.999 & & & & & & \\
\hline 10 & $\begin{array}{l}6.843 \mathrm{E}- \\
5\end{array}$ & .001 & 100.000 & & & & & & \\
\hline
\end{tabular}

Table 8 highlights the Component Matrix after extraction and rotation. After extraction and rotation, the Component Matrix has four main axes:

- The first axis relates to: training in the use of braille, braille skills, being employed, and the character of the source of income;

- The second axis relates to: training in the use of braille, braille skills, being employed, and the character of the source of income;

- The third axis is related to: the ability to access information through adapted computer technology in voice synthesis or braille output;

- The fourth axis is related to: occupation and the adapted educational training received. 
Table 8 Component Matrix after extraction and rotation

\begin{tabular}{|l|l|l|l|l|}
\hline Socio-economic variables & Components & & & \\
\cline { 2 - 5 } & $\mathbf{1}$ & $\mathbf{2}$ & $\mathbf{3}$ & $\mathbf{4}$ \\
\hline Level of education & -.104 & -.096 & -.829 & .253 \\
\hline Occupation & -.002 & -.082 & -.098 & .754 \\
\hline Have received braille training & .995 & .975 & .103 & .029 \\
\hline Braille skills & .995 & .975 & .108 & .034 \\
\hline Have received adapted academic training & .047 & .400 & .115 & .675 \\
\hline Have received adapted vocational training & .463 & -.092 & -.119 & .410 \\
\hline Able to access information through adapted computer technology & .095 & .110 & .870 & .146 \\
\hline Is employed & .936 & .062 & .030 & .035 \\
\hline Character of source of income & .793 & .761 & .191 & -.080 \\
\hline Income level & -.814 & -.188 & -.098 & -.089 \\
\hline
\end{tabular}

\section{Discussion}

The objective of the study conducted in Yaoundé was to determine the socio-economic factors associated with the deterioration of the quality of life and their influence on the autonomy of visual impairment persons aged 15 years and over, residing in Yaoundé.

From this study, it emerged that there is a relationship between the level of autonomy and the following variables: level of education, occupation, braille training received, braille skills, adapted school training received, access to information through computer with voice synthesis or braille output, employment status, income level and the nature of the source of income (Chi-square; $\mathrm{p}<0.05$ ). With regard to the autonomy, there are differences between occupation groups, education level, income level, and groups according to the character of the source of income (One-way ANOVA; $<<0.05$ ). There is a strong relationship between the level of autonomy and the employment status of the individual (Cramer's $\mathrm{V}$ $>0.7 ; \mathrm{p}<0.05$ ). After raw PCA extraction, occupation and having skills in braille use are of good quality in terms of percentage variance. After readjustment, having braille-using skills still retains that quality. In addition, braille training, braille skills, and income source character are well represented on the major axes even after rotation.

Blindness and visual impairment have a broad social impact [6]. Social and economic factors such as income, education and social background can have a direct impact on health. A study in Cameroon showed that poverty and economic problems are barriers for more than $5 \%$ of people with disabilities [7]. Visual impairments reduce independence in daily life [8]. People with very low incomes often lack resources and have limited access to food, adequate housing and safe walking paths and working conditions. They may experience financial hardship and stress. However, these effects are still a function of personal and work demands and the ability to manage and influence decision making. Increased stress levels and a lack of resources, skills, social support and community belonging can lead to inadequate coping skills. Financial considerations certainly play a role, but are not the only parameter. The presence of financial means will help some, but if they are lacking, they will push people with disabilities who lack them into loneliness, isolation and even more poverty [9]. People living in extreme poverty do not have access to basic services, and often face dangerous living conditions. This greatly increases the likelihood of deteriorating their health status to a greater or lesser extent and causing impairments or disabilities. Ultimately, people with disabilities are likely to face social exclusion and discrimination, further exacerbating their poverty and vulnerability [10]. Thus, a person experiencing poverty will not have sufficient material resources and will live in conditions that do not allow him or her to exist with dignity according to legitimate and vital human rights. Disability is a factor of social fragility and implies material difficulties of existence. It is true that financial dependence increases precariousness, but precariousness as such is not only linked to income criteria, but also depends on the degree of dependence on benefits [11].

Depending on the seriousness of the disability, the economic and social consequences can be more or less discriminatory and generate situations of precariousness, even poverty [12]. Precariousness limits travelling due to lack of means and therefore favors unsuitable and dangerous transport conditions. It makes access to education, training 
and employment difficult [12]. Precariousness and disability are intimately linked, and this link is an extension of social inequalities. Very often, precariousness aggravates disability. Precariousness induces lifestyles outside the socially dominant norms (housing, food, hygiene, environment). In developing countries, $82 \%$ of people with disabilities live below the poverty line and represent 15 to $20 \%$ of the poor [12]. Precariousness restricts the possibility of care, and thus the possibility of good health weakened by possible addictions. Just as disability generates discriminatory reactions, precariousness contributes to social exclusion [12].

People with disabilities, who are more often victim of discrimination and marginalization, do not always benefit from appropriate education and vocational training to access the labor markets and information and communication technologies. As for children and adolescents with sensory (hearing and visual impairments) and mental disabilities, who benefit from special education, i.e. training that combines pedagogical, psychological, social, medical and paramedical activities, the State, families and natural or legal persons do not give them the same attention $[13,14,15]$. More than $3 \%$ of persons with disabilities have problems to accessing education. On the basis of their disability, they have difficulties to being admitted to secondary schools of their choice [7]. A large proportion of persons with disabilities remain undereducated because families consider sending them to school as a non-productive expense, a waste of time and energy. In poor countries, a large majority of children with disabilities do not have access to education. It is more difficult for a young person with disabilities to pursue a long education than for an able-bodied young person, in particular because of the problems of accessibility and human support inherent to their disability [10, 16, 17]. Exclusion from education further accentuates the vicious circle of disability and poverty. The disabled population is relatively old and generally has few qualifications. Even in the 25-49 age group, one among two people with a disability that limits their capacity for work or is recognized by the authorities have no professional or higher education qualifications. The proportion of those who hold a Certificate of Professional Aptitude or General Certificate of Education Ordinary Level is close to the average, but Advance Level holders are relatively rare [18]. Many teachers believe in the educational value of integration, but remain reluctant to welcome disabled students into their own classrooms. This situation, which is paradoxical to say the least, reveals the difficulty of breaking with the past and taking a new step in the educational care of atypical children [19].

To compensate for the vision deficit, the visual impairment person must develop strategies to access information. Visually impaired persons have access to information via audio media. They give preference to radio, television and all audio messages. Printed materials are accessible only if they are in Braille. These adapted documents are rare. The Internet is a real opportunity for information and communication, provided that the sites are designed with accessibility in mind [20]. People who are visual impairment or very severely visually impaired cannot directly access written information, even from digital sources. They need an interface that processes the information, rendering it to the visual impairment user in a form that is accessible to him or her, Braille or text-to-speech for text and 3D for images [21]. Nowadays, the vast majority of websites are difficult to access. The use of adapted hardware such as computer interfaces (software that reads aloud or renders in Braille what is displayed on the screen) improves reading comfort. However, these tools do not solve everything, especially since they are not used often because of their cost, the steps to be taken to obtain them, the difficulty of using them or lack of awareness of their existence [20]. Information literacy is a major issue in social relations in our modern societies, both for communities and for individuals [21].

The slow and difficult achievement of the cultural autonomy of visually impaired persons has been marked by the invention of Braille, mass sound supplies, and today information and communication technologies. These steps have each been embodied by a technique that has significantly improved the previous situation, by giving access to new sources of information. Thus, a vast network and the generalization of the circulation of digitized information, give the visual impairment and partially visually impaired people easier access to all the activities of social life [21]. In 2009, a European survey raised up a real concern for the accessibility of information content on the Internet for people with disabilities: less than $10 \%$ of the sites that had been assessed, did not comply with the international accessibility standards [22]. There are still many impediments to apply these standards when building a website. A series of interviews with web professionals revealed many hindrances and a stereotypical view of the concept of accessibility [22].

Access to employment is an area in which much discrimination against people with disabilities persists and accentuates precariousness [23]. Inequalities in access to employment are accompanied by greater constraints and less autonomy. This observation will become alarming in a context of unemployment and exclusion. Living in a situation of high dependency often abolishes the right of each person to carry out his or her own life project [12]. The unemployment rate in the disabled population is higher than in the rest of the population. It is logical that in these conditions, the disabled person is more vulnerable. Visually impaired persons therefore feel very threatened by the trap of unemployment and non-employment. The unemployment rate of people with disabilities is on average $80 \%$ higher than 
that of other people [12]. The employment rate is low and one of the reasons for this is the mismatch between the qualifications of people with disabilities and the expectations of employers.

As for job offers in sheltered work establishments, they are limited in view of the broadening of the notion of workers and the obligation of results imposed on the Institutions and Services of Assistance through Work. These conditions not only generate work-related fears, but also weaken visually impaired persons more generally, and their confidence is undermined in several areas other than working life. Consequently, the low employability of these people leads to a low standard of living [12]. More than 4\% of people with disabilities noted the existence of barriers and obstacles related to access to work [7]. Employers very often refuse to recruit them on the simple fact that people with disabilities will not be able to perform to the same level as others, as their mobility for business needs is reduced. People who are employed and who are in a situation of ill-being at work are also more likely to report lower satisfaction [24]. Thus, the greatest permeability to ill-being is observed in situations of great social fragility [11]. Beyond being a source of income, work is a vector of fulfilment through participation in social life. Work is an essential part of life. It supports identity, contributes to personal fulfillment, self-fulfillment, and recognition of oneself and others [23] Stressful experiences arise from having to deal with low income, food insecurity, inadequate working conditions, job insecurity, and various forms of discrimination based on disability status [25].

\section{Conclusion}

Blind and visual impaired persons who have sustainable employment, a sufficiently high level of income and a sustainable source of income, have a higher level of independence with the contribution of other socio-economic factors. Socio-economic factors associated with a decline in quality of life interact with and influence the autonomy of the visual impairment person to varying degrees. We advocate that schools, businesses and local institutions provide visually impaired persons with free access to education, work and resources.

\section{Compliance with ethical standards}

\section{Acknowledgments}

The authors would like to thank the visual impairment persons of the city of Yaoundé for agreeing to take part in this study.

\section{Disclosure of conflict of interest}

The authors declare no conflict of interest.

\section{Statement of informed consent}

Informed consent was obtained from all individual participants included in the study.

\section{References}

[1] Ministry of Public Health. Health Sector Strategy 2001-2015. Yaoundé-Cameroon, 2009.

[2] Baheu E, Hazebrouck CH. Autonomy and independence. Faculty of Lille. 2012.

[3] Letzelter N. Life Quality Studies in Ophthalmology: Interests and Applications Concerning Cataracts, Chronic Glaucoma at an Open Angle, and Macular Degeneration in Aging. Chauvin Bausch and Lomb Laboratory. 2001.

[4] World Health Organization. Study protocol for the World Health Organization project to develop a Quality of Life assessment instrument (WHOQOL). Quallity Life Research. 1993; 2 (2): 153-159.

[5] Hu Y, Mak JNF, Wong YW, Leong JCY, Luk KDK. Quality of life of traumatic spinal cord injured patients in Hong Kong. Journal of Rehabilitation Medicine. 2008; (40): 126-131.

[6] Resnikoff S, Pararajasegaram R. From policy to action. City prevention programs: past, present and future. 2001.

[7] African Union des Aveugles. (UAFA) and the National Association of Aveugles of Cameroon (ANAC) in partnership with the International Promotion of the Rights of Persons with Disabilities of Canada and the Swedish Association of Disabled Persons and Disabled People. Study on the rights of disabled people in Cameroon. Imprimerie natioanle. 2007. 
[8] Sander M-S, Bournot M-C, Lelièvre M, Tallec A. People with a visual impairment: The contribution of the Disability-Disability-Dependency survey. 2012.

[9] Poizat D. Represes on Inclusion: Monde, Europe, France. Reliance. 2006; 4 (22): 99-103.

[10] Handicap International. Inclusive education. Geneva. 2012.

[11] National Institute of Statistics and Economic Studies, France. Permanent Surveys on Household Living Conditions (EPCV). Yaoundé. 2003; 140.

[12] Ecole des Hautes Etudes en Santé Publique, France. Interprofessional module on public health. Paris. 2010.

[13] Ministry of Social Affairs, Cameroon. Practical guide on the accessibility of people with disabilities in education. Yaoundé. 2010.

[14] World Health Organization. Global report on disability. Geneva. 2011.

[15] Organization of the United Nations. Convention relating to the Rights of Persons with Disabilities and Optional Protocol. Geneva. 2008.

[16] Law No. 2010/002 of 13 April 2010 concerning the protection and promotion of disabled people in Cameroon.

[17] Organization of the United Nations. Follow-up of the Convention on the Rights of Persons with Disabilities. Guide to Intentional Observers of Human Rights. Series on vocational training. Washington, 2010, $\mathrm{n}^{\circ} 17$.

[18] Amira S, Meron M. The professional activity of people with disabilities. France, social portrait. 2004; 173-93.

[19] Gardou C. The school integration of disabled children at the threshold of a new phase. Or how to pass the intentions to the acts. European Review of Mental Disability. 1998; 5 (17): 3-10.

[20] Allaire C. National Institute for Health Prevention and Education (France). Inform the blind or malicious people: sharing experiences. Saint-Denis, INPES. 20.

[21] Descargues B. The accessibility of new information and communication technologies to avian and malignant people. Report to Madame the Minister for the Employment of Solidarity and to Madame the Secretary of State for Health and the Disabled. Paris, 2000. Accessed March 23, 2019 at https://www.viepublique.fr/rapport/24400-laccessibilite-des-nouvelles-technologies-de-linformation-et-de-la-com

[22] Demontoux F, Fremont H, Woirgard E. Improving the EEA Education Accessibility Training for Disabled Students: Towards a Mutualization of Experiences and a Generalization of Practical Benefits. In CETSIS 2013: Teaching of the Technologies and Sciences of Information and Systems. Caen, 2013, pp. 1-10.

[23] Camille B. The insertion of people in situations of disability in the ordinary environment: what challenges for the company? Lyon University of Light 2, Institute of Political Studies of Lyon, Seminary Memorial. 2010, 97 p.

[24] Amiel MH, Godefroy P, Lollivier S. Quality of life and well-being are often paired. Paris, 2013.

[25] Mikkonen J, Raphael D. Social determinants of health the Canadian facts. Toronto: York University, School of Health Policy and Management, 2010,63 p. 